\title{
Bacharelado interdisciplinar: uma proposta inovadora na educação superior em saúde no Brasil
}

\author{
Interdisciplinary Bachelor's degree in Health: \\ an innovative proposal in higher education in Health in Brazil
}

Carmen Fontes de Souza Teixeira ${ }^{1}$

Maria Thereza Ávila Dantas Coelho ${ }^{1}$

Marcelo Nunes Dourado Rocha ${ }^{1}$

${ }^{1}$ Instituto de Humanidades, Artes e Ciências Prof. Milton Santos, Universidade Federal da Bahia. R. Barão de Jeremoabo s/n, Ondina. 40.170-115 Salvador BA. carment@ufba.br

\begin{abstract}
This article describes and analyzes the political and institutional context and the process of implementation of the Interdisciplinary Bachelor's degree in Health (IBH) during the 20062011 period. The methodology included document review and analysis of personnel records of the researchers involved. By using the concepts of "window of opportunity" and "hypercomplex organization," it was revealed that managerial and organizational structures were created and master-documents were prepared. In addition to this, actions for implementation of the course, related to the structure of the faculty and the academic council, preparation of the pedagogical project, planning, implementation and monitoring of the teaching-learning process in the various curriculum components offered since 2009 was conduct$e d$. Analysis of the challenges and prospects of the course indicates that the major problem is the tension between the traditional model of vocational and discipline-based higher education existing hitherto and the interdisciplinary model proposed by IBH. This tension can be overcome by the full implementation of learning cycles with the institutionalization of IBH as the first cycle of professional health education.
\end{abstract}

Key words Human resources training, Higher education in health, Premedical Education, Interdisciplinary Bachelor's degree in Health, University
Resumo Este artigo descreve e analisa o contexto político-institucional e o processo de elaboração e implantação do Bacharelado Interdisciplinar em Saúde (BIS) no periodo 2006-2011. A metodologia utilizada incluiu revisão documental e análise dos registros pessoais dos pesquisadores envolvidos. A partir dos conceitos de "janela de oportunidade" e "organização hipercomplexa", verificou-se que foram criadas estruturas gerenciais e organizativas, elaborados documentos-mestres $e$ desencadeadas ações para a implantação do curso, ligadas à conformação do corpo docente e do Colegiado do curso, elaboração do Projeto Pedagógico, planejamento, execução e acompanhamento do processo ensino-aprendizagem nos diversos componentes curriculares. A análise dos desafios e perspectivas do curso aponta que o maior problema enfrentado é a tensão entre o modelo de formação superior, profissional e disciplinar, existente até então e o modelo interdisciplinar proposto pelo BI, tensão que pode ser superada pela implantação do regime de ciclos, com a institucionalização do BI como primeiro ciclo da formação profissional na área de saúde.

Palavras-chave Formação de recursos humanos, Educação superior em saúde, Educação prémédica, Bacharelado interdisciplinar em saúde, Universidade 


\section{Introdução}

A formação de pessoal em saúde apresenta, como questão central, as limitações dos modelos de formação vigentes diante das demandas e necessidades decorrentes da construção do Sistema Único de Saúde (SUS) ${ }^{1}$ e da recomposição do setor privado, nas últimas décadas ${ }^{2,3}$. De fato, a reorientação das políticas e as mudanças na produção, distribuição e consumo de serviços tem gerado mudanças significativas na organização do processo de trabalho em saúde, afetando, direta e indiretamente, a formação dos profissionais e dos trabalhadores. Observa-se, assim, uma tendência à fragmentação do processo de trabalho e diversificação das formas de inserção dos profissionais no mercado e multiplicação de vínculos empregatícios ${ }^{4,5}$.

Desse contexto fazem parte instituições responsáveis pela formação de pessoal, constatando-se a extraordinária expansão do número de escolas e cursos na área de saúde, notadamente no setor privado, embora de forma desigual, dado a existência de fortes movimentos de "reserva de mercado" por parte de algumas categorias profissionais ${ }^{6}$. No âmbito dos cursos observa-se o desencadeamento de reformas curriculares estimuladas pela aprovação da nova Lei de Diretrizes e Bases para a Educação ${ }^{7}$ que confere liberdade às instituições de ensino para o desenho de currículos inovadores, adequados às realidades regionais e às vocações das escolas, substituindo-se o antigo "currículo mínimo" pelas Diretrizes Curriculares Nacionais (DCN).

Especificamente na área da saúde, as DCN reforçam a necessidade de orientar a formação dos profissionais ${ }^{8}$, ao tempo em que as instituições gestoras do SUS têm formulado políticas de educação permanente e gestão do trabalho que visam readequar perfis profissionais às necessidades do sistema, valorizar o trabalhador e promover a humanização da atenção ${ }^{4,5,9}$.

Apesar disso, é forçoso admitir que o perfil (científico-técnico e ético-político) dos profissionais formados continua predominantemente direcionado à reprodução do modelo médico-assistencial hegemônico, que subsiste mesmo ao interior do SUS ${ }^{10}$, o que, em parte, deriva da permanência de um modelo de formação superior que enfatiza a profissionalização precoce, com tendência à especialização e subespecialização, contribuindo para tornar os profissionais formados dependentes tecnologicamente e carentes de capacidade crítica diante das transformações na situação de saúde e na organização do trabalho no setor.
Mais recentemente, propostas de mudança nas políticas e na organização da atividade universitária em diversos países do mundo ${ }^{11-16}$ têm repercutido no Brasil, a exemplo da Universidade Federal da Bahia (UFBA), que introduziu mudanças em sua arquitetura acadêmica, entre as quais os cursos de Bacharelado Interdisciplinar (BI) nas áreas de Artes, Humanidades, Ciência e Tecnologia e Saúde. O objetivo deste trabalho é descrever e analisar o processo de elaboração e implantação do Bacharelado Interdisciplinar em Saúde (BIS) no período 2006-2011. A metodologia utilizada incluiu extensa revisão documental, bem como a análise dos registros pessoais efetuados pelos pesquisadores, envolvidos na implantação do curso.

\section{Contexto político-institucional}

A proposta de criação dos Bacharelados Interdisciplinares (BI) surgiu no contexto de formulação do projeto "UFBA Nova" ${ }^{17}$, em discussão desde 2006, cujo principal objetivo era a reestruturação do ensino de graduação através da implantação do regime de ciclos. O BI foi compreendido como o primeiro ciclo do processo de formação superior, em caráter não profissionalizante, constituindo uma etapa preparatória para a continuidade da formação profissional e acadêmica $^{18}$ (Figura 1).

O debate em torno da inclusão da UFBA no Programa de Apoio a Planos de Expansão e Reestruturação das Universidades Federais (REUNI) representou uma verdadeira "janela de oportunidade" ${ }^{19,20}$, sendo que o Plano aprovado incluiu a criação dos $\mathrm{BI}$, mas manteve o ingresso direto nos tradicionais cursos profissionalizantes pelo processo seletivo do vestibular, prevendo-se uma gradativa transição de ao menos parte de suas vagas para ingresso através dos $\mathrm{BI}^{21}$.

Inicialmente formulado como um curso, a proposta apresentada, em julho de 2008, à Câmara de Ensino de Graduação (CEG) contemplava a implantação de quatro cursos de Bacharelado Interdisciplinar (BI): Ciência \& Tecnologia, Humanidades, Artes e Saúde. De acordo com a proposta aprovada, os BI são:

“... uma modalidade de curso de graduação que se caracteriza por agregar uma formação geral humanística, científica e artística ao aprofundamento num dado campo do saber, promovendo o desenvolvimento de competências e habilidades que possibilitarão ao egresso a aquisição de ferramentas cognitivas que conferem autonomia para aprendizagem ao longo da vida 


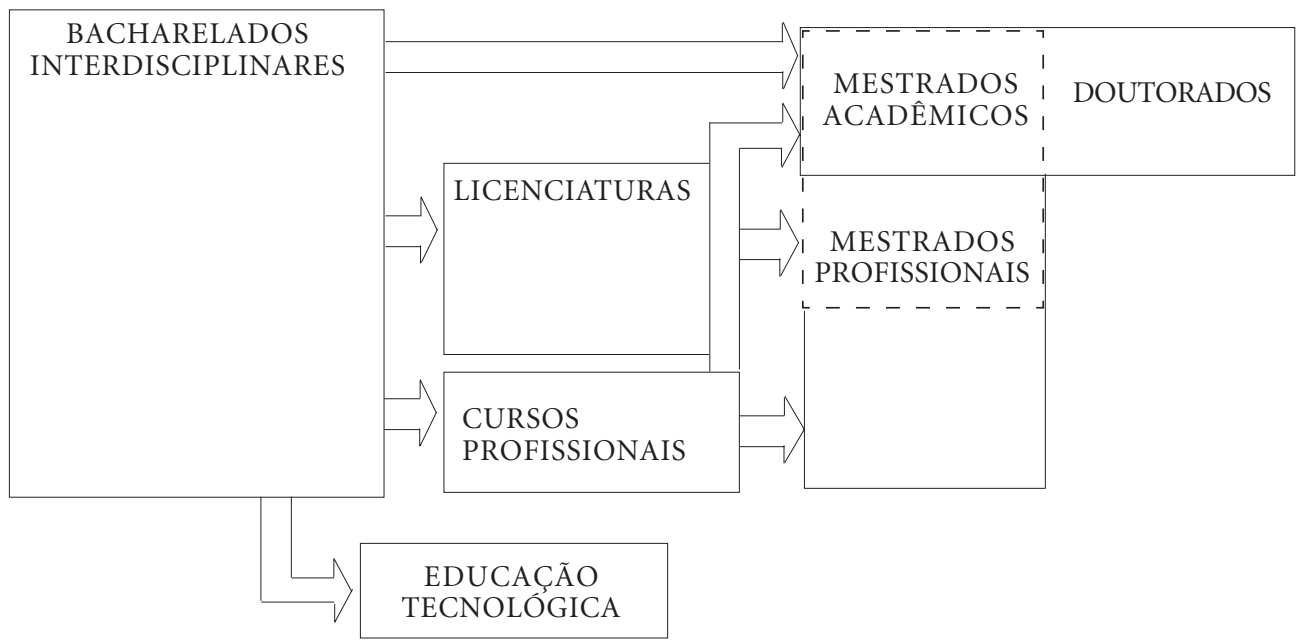

Figura 1. Arquitetura curricular da Universidade Nova.

Fonte: UFBA. Projeto Pedagógico dos Bacharelados Interdisciplinares, 2008 (adaptado).

bem como uma inserção mais plena na vida social, em todas as suas dimensões. Também provê fundamentos conceituais e metodológicos para a formação profissional em cursos de graduação que o adotem como primeiro ciclo"22.

O projeto político-pedagógico dos BI estabeleceu cinco princípios norteadores para a construção dos currículos específicos nas grandes áreas do conhecimento ${ }^{22}$ :

. Autonomia - implica na responsabilização do indivíduo na condução do seu próprio processo de aprendizagem. Constitui-se em requisito fundamental para consolidação de sua competência de aprender a aprender.

. Flexibilidade - diminuição ao mínimo necessário da exigência de pré-requisitos, favorecendo a possibilidade de escolha livre pelos alunos dos componentes a serem cursados e, como consequência, reforçando o princípio da autonomia.

. Articulação - propõe a criação de componentes curriculares de natureza interdisciplinar, bem como sugere o acréscimo de outros dispositivos, de natureza integradora, tais como Seminários, Oficinas e Laboratórios.

. Atualização - revisão e atualização periódica dos componentes curriculares buscando contemplar os avanços científicos, tecnológicos, as inovações artísticas e quaisquer novidades no campo do conhecimento.
. Inclusão das três culturas - deverão incluir componentes curriculares que representem e articulem os três grandes campos do conhecimento, contemplando conteúdos dos campos artístico, científico e humanístico.

Para sediar os BI, foi criada uma nova unidade acadêmica, o Instituto de Humanidades, Artes e Ciências Prof. Milton Santos (IHAC), cujo objetivo inclui "fomentar uma configuração MIT (multi, inter, trans) disciplinar do conhecimento, mediante a oferta de programas interdisciplinares de graduação e pós-graduação, além da pesquisa, criação e inovação produzidas em centros de pesquisa e extensão"23,24.

\section{O projeto pedagógico do BI Saúde}

A implantação dos cursos começou com a indicação dos coordenadores através de portaria do reitor, em outubro de 2008. A elaboração do projeto pedagógico do BIS coube inicialmente à coordenadora do curso, que revisou o "projeto original" e a "Matriz curricular do BI Saúde"25, na qual se especificava os eixos estruturantes comuns aos BI e o conteúdo específico do BIS, abarcando os "níveis de determinação" ${ }^{26}$ do processo saúde-doença e os níveis de organização das práticas de saúde.

Tal proposta, entretanto, não apresentava a disponibilidade desses conhecimentos nas disci- 
plinas oferecidas pelos diversos cursos da UFBA, nem uma análise prospectiva da oferta de componentes curriculares (antigos e novos) que pudessem vir a compor a "grade" curricular do BIS. A primeira versão do projeto pedagógico do BIS foi desenvolvida de fevereiro a abril de 2009, buscando atender a três princípios: 1) preservação das diretrizes do projeto pedagógico preliminar e geral dos BI; 2) incorporação das ideias surgidas nas discussões realizadas pela Congregação do IHAC; 3 ) autonomia do Colegiado para propor um projeto que contivesse uma arquitetura geral comum e comportasse os conteúdos próprios a cada campo (Figura 2).

Os documentos elaborados pelos Colegiados foram aprovados pela Congregação Ampliada do IHAC em abril e encaminhados para a CEG, em maio, sendo submetidos à avaliação técnica. O parecer preliminar, emitido em julho, recomendou revisão dos projetos, sendo a segunda versão encaminhada em dezembro. Diante das críticas e recomendações emitidas, os projetos foram revisados mais uma vez, durante os meses de março e abril de 2010 e reencaminhados à CEG. Os principais ajustes foram feitos nos itens referentes às competências e habilidades do egresso (maior concisão), forma de avaliação (maior detalhamento), matriz curricular (alteração da quantidade e definição dos componentes obrigatórios da formação específica em saúde, apresentação dos critérios das Atividades Complementares, com alteração de sua carga horária).

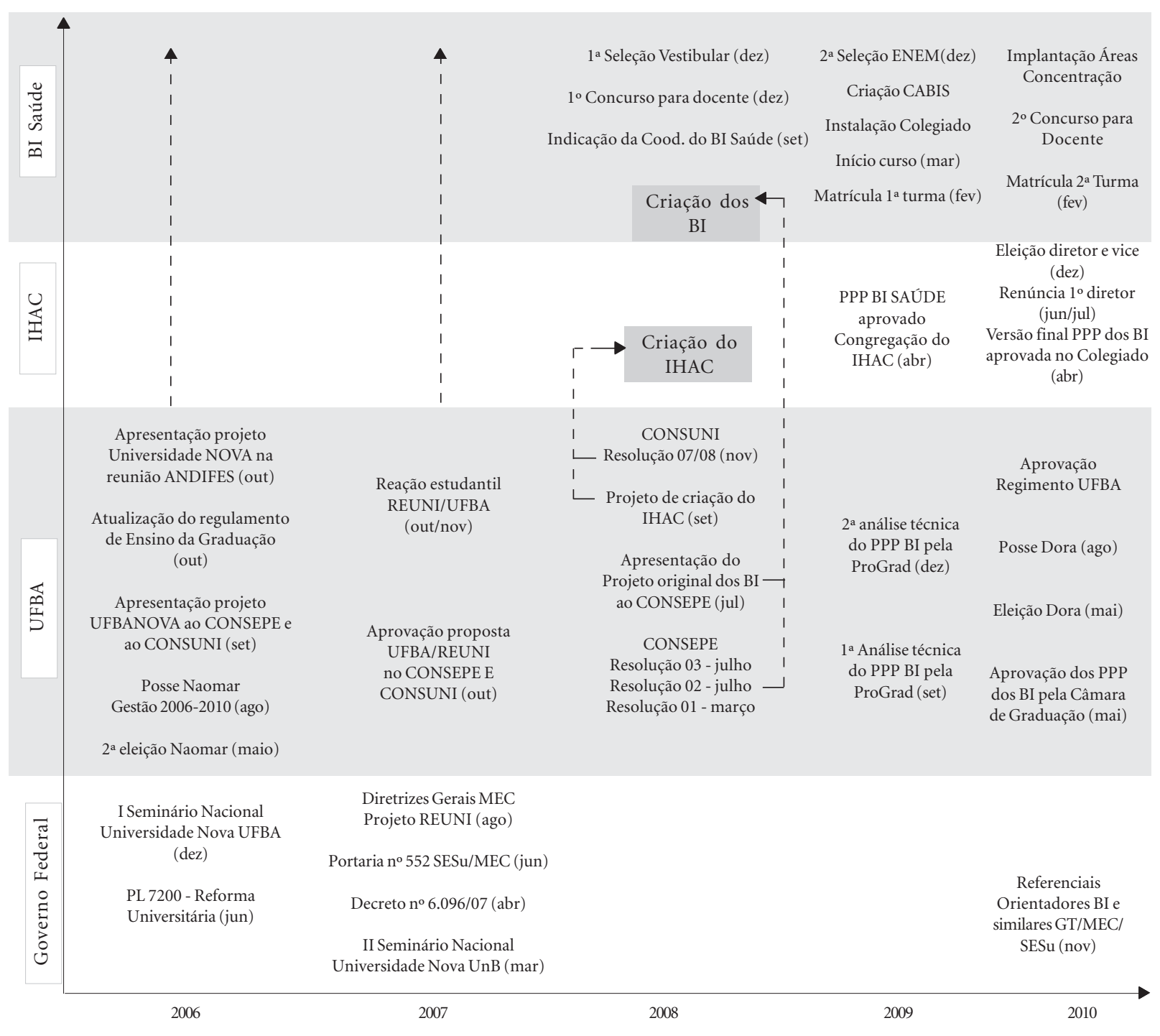

Figura 2. Linha do tempo do processo de criação, formulação e implantação do BI Saúde: 2006 - 2010. 
O parecer final juntamente com a última versão revisada do projeto foi avaliado pela CEG sendo finalmente aprovado em maio de 2010.

O projeto pedagógico aprovado reafirma que o BIS é "um curso de graduação de duração plena que visa agregar uma formação geral humanística, científica e artística ao aprofundamento no campo da saúde, promovendo o desenvolvimento de competências e habilidades que conferem autonomia para a aprendizagem e uma inserção mais abrangente e multidimensional na vida social (...)"27.

O perfil do egresso (Quadro 1) enfatiza competências gerais relacionadas com a capacidade de "aprender a aprender", competências cognitivas e habilidades específicas que permitem ao estudante compreender a complexidade do campo da saúde na contemporaneidade e acrescenta um conjunto de valores relacionados com o processo de sensibilização para questões cruciais do mundo atual, como a luta pelos direitos humanos, a preservação do meio-ambiente, a defesa dos princípios democráticos e a valorização da diversidade cultural que caracteriza a sociedade brasileira e baiana, em particular.

A especificação e distribuição dos diversos componentes curriculares resultaram do esforço de "tradução" dos diversos "Eixos estruturantes" contidos no projeto original às possibilidades abertas com a criação do IHAC e, ao mesmo tempo, às condições operacionais oferecidas pela manutenção da arquitetura acadêmica e estru- tura curricular dos diversos cursos oferecidos pelas unidades da UFBA. Com isso, se por um lado foi possível incluir novos componentes curriculares, como é o caso de "Estudos da contemporaneidade", realizados integralmente pelos docentes do IHAC, por outro, ajustou-se a oferta dos componentes à capacidade de oferta da Universidade, o que resultou na manutenção de "Língua portuguesa" como obrigatória e na inserção de "Língua estrangeira moderna", no elenco de "Culturas" (Quadro 2).

No que diz respeito à Formação Específica em Saúde, os componentes curriculares obrigatórios apresentam uma visão panorâmica do campo, incluindo o debate do conceito de Saúde do ponto de vista histórico, sociológico, antropológico, político e cultural, a análise comparada de sistemas de saúde no mundo contemporâneo, a análise das relações entre o sistema público e o sistema privado de saúde no Brasil e as características das diversas profissões de saúde em nosso meio, analisando as tendências do mercado de trabalho e da formação profissional.

O componente curricular "Oficina de textos acadêmicos e técnicos em saúde" completa o eixo "linguagens" e discute as múltiplas formas de expressão e comunicação dos conhecimentos e tecnologias produzidos e difundidos na área de Saúde. Inclui a leitura e análise de artigos científicos, resenhas, projetos, relatórios de pesquisa, documentos institucionais, leis, portarias, planos, programas e projetos de intervenção no campo da saúde.

Quadro 1. Perfil do egresso do Bi saúde

\begin{tabular}{|c|l|}
\hline $\begin{array}{c}\text { Competências } \\
\text { e habilidades gerais }\end{array}$ & $\begin{array}{l}\text {. Capacidade de abstração, análise e síntese de conhecimentos; } \\
\text {. Habilidades para buscar, processar e analisar informação procedente de } \\
\text { fontes diversas; } \\
\text {. Capacidade de comunicação oral e escrita em língua portuguesa; } \\
\text {. Habilidades no uso das tecnologias da informação e da comunicação; }\end{array}$ \\
\hline $\begin{array}{c}\text { Competências e } \\
\text { habilidades específicas }\end{array}$ & $\begin{array}{l}\text { - Compreender a complexidade do campo da saúde nas sociedades } \\
\text { contemporâneas; } \\
\text { - Identificar e analisar problemas de saúde no âmbito individual e coletivo; } \\
\text {. Analisar políticas públicas, programas e projetos da área de saúde; } \\
\text { - Identificar e analisar as tendências do mercado de trabalho e das práticas } \\
\text { profissionais em saúde. }\end{array}$ \\
\hline $\begin{array}{c}\text { Competências } \\
\text { valorativas e } \\
\text { compromissos éticos }\end{array}$ & $\begin{array}{l}\text {. Responsabilidade social e compromisso cidadão; } \\
\text { - Valorização e respeito pela diversidade cultural; } \\
\text {. Consolidação dos valores democráticos na sociedade contemporânea; } \\
\text {. Preservaçấo do meio ambiente; } \\
\text {. Compromisso ético-político no campo da saúde. }\end{array}$ \\
\hline
\end{tabular}

Fonte: UFBA, IHAC. Projeto Pedagógico do Bacharelado Interdisciplinar em Saúde, 2010. 
Quadro 2. Síntese da distribuição da carga horária do curso.

\begin{tabular}{|c|c|c|}
\hline Eixo/Módulos & Componente Curricular (CC) & $\mathrm{CH}$ \\
\hline Módulo Interdisciplinar & $\begin{array}{l}\text { HAC A01 - Estudos sobre a Contemporaneidade I } \\
\text { HAC A34 - Estudos sobre a Contemporaneidade II }\end{array}$ & $\begin{array}{l}68 \mathrm{~h} \\
68 \mathrm{~h}\end{array}$ \\
\hline Módulo Culturas & $\begin{array}{l}2 \text { CC Cultura humanística (a escolher) } \\
2 \text { CC Cultura artística (a escolher) }\end{array}$ & $\begin{array}{l}136 \mathrm{~h} \\
136 \mathrm{~h}\end{array}$ \\
\hline Eixo Linguagens & $\begin{array}{l}\text { LET E43 Língua Portuguesa, Poder e Diversidade } \\
\text { LET E45 Leitura e Produção de Textos em Língua Portuguesa } \\
\text { HAC Oficina de Textos Acadêmicos e Técnicos em Saúde }\end{array}$ & $\begin{array}{l}68 \mathrm{~h} \\
68 \mathrm{~h} \\
68 \mathrm{~h}\end{array}$ \\
\hline $\begin{array}{l}\left.\text { Formação específica( } 1^{\text {a }} \text { etapa }\right) \\
\text { CC Obrigatórios }\end{array}$ & $\begin{array}{l}\text { HAC A10 - Introdução ao Campo da Saúde } \\
\text { HAC A40 - Campo da Saúde: Saberes e Práticas } \\
\text { HAC - Saúde, Educação e Trabalho }\end{array}$ & $\begin{array}{l}68 \mathrm{~h} \\
68 \mathrm{~h} \\
68 \mathrm{~h}\end{array}$ \\
\hline $\begin{array}{c}\text { Formação específica(2a etapa) } \\
\text { CC optativos }\end{array}$ & 11 CC oferecidos pelas unidades de saúde e/ou pelo IHAC & $748 \mathrm{~h}$ \\
\hline \multicolumn{2}{|l|}{$\begin{array}{l}\text { Subtotal } \\
\text { Atividades complementares } \\
\text { Componentes livres ( } 7 \text { CC de } 68 \text { h) } \\
\text { Total geral }\end{array}$} & $\begin{array}{r}1020 \mathrm{~h} \\
360 \mathrm{~h} \\
476 \mathrm{~h} \\
2400 \mathrm{~h}\end{array}$ \\
\hline
\end{tabular}

Fonte: UFBA, IHAC. Projeto Pedagógico do Bacharelado Interdisciplinar em Saúde, 2010.

Os componentes optativos (748 h) são escolhidos do elenco de componentes oferecidos pelas unidades de saúde da UFBA aos alunos do BIS no momento da matrícula semestral. As atividades complementares (360 horas) abarcam um conjunto de atividades de pesquisa, extensão, estágio, programas especiais, cursos livres, monitoria em disciplinas de graduação e atividade curricular em comunidade.

Finalmente, contempla-se a inserção dos estudantes do BIS em componentes curriculares nomeados Livres, os quais podem ser escolhidos de acordo com a disponibilidade de oferta de quaisquer das unidades da UFBA, "desde que os respectivos colegiados facultem o ingresso aos alunos do BI respeitando-se as especificidades e os pré-requisitos (onde estes existam)"27.

\section{A implantação}

do bacharelado interdisciplinar em saúde

A implantação do BIS contemplou, em 2009, um conjunto de iniciativas destinadas à criação de condições gerenciais, organizativas e operacionais para a execução do curso, quais sejam a conformação do corpo docente, a organização do Colegiado e da secretaria, o planejamento acadêmico da oferta de componentes curriculares, a recepção aos alunos e o acompanhamento do processo de ensino-aprendizagem nos diversos componentes.

\section{Conformação do corpo docente}

No primeiro semestre do curso, a equipe docente do BIS contava com apenas duas professoras com formação específica na área, as quais assumiram as funções de coordenação e vice-coordenação, bem como os componentes curriculares da área. Em 2010, foram contratados três professores substitutos, ao tempo em que se operava a redistribuição de dois docentes de outras Universidades que solicitaram transferência para o IHAC, tendo sido realizado concurso público para docentes no segundo semestre de 2010 com a contratação, em 2011, de cinco aprovados. Com isso, a equipe do BIS passou a dispor de nove docentes, aos quais se agregou, em 2011, um do ISC em tempo parcial e um professor substituto.

\section{Número e Perfil dos alunos matriculados}

Em 2009, foram oferecidas 100 vagas no turno noturno, preenchidas com os candidatos aprovados no Vestibular. A partir de 2010, o 
IHAC adotou a forma de ingresso através do ENEM e ampliou o número de vagas do BIS para 300 (200 no turno noturno), as quais não chegaram a ser totalmente preenchidas devido aos problemas ocorridos com o ENEM naquele ano, que ocasionaram a realização de apenas uma convocação complementar à primeira. Já em 2011, mantido o número de vagas, foi efetuada a matrícula em três momentos subsequentes (primeira, segunda e terceira chamada), resultando no preenchimento da maioria delas.

Dos alunos matriculados em 2009, 74 \% tinham menos de 24 anos, sendo que $40 \%$ tinham entre 16 a 19 anos. Apenas 11\% do total eram maiores de 30 anos, chamando a atenção a presença de um aluno de mais de 50 anos. Quanto ao sexo, observou-se uma discreta maioria de mulheres (58\%). A maior parte provinha de escolas particulares (67\%) e 71\% informaram não ter formação prévia, sendo o BI a sua porta de entrada na Universidade. Dos demais, $12 \%$ informaram já ter concluído um curso de graduação, dos quais mais da metade na área de Saúde, sendo que $15 \%$ haviam passado por outros cursos, sem haverem concluído.

Os alunos que ingressaram em 2010 e 2011 apresentam algumas características semelhantes e outras diferentes, em virtude, provavelmente, da mudança dos procedimentos de ingresso ao curso. A maioria tem menos de 24 anos de idade, é do sexo feminino, proveniente de escolas públicas, não tem formação prévia e pretende, ao concluir o curso, fazer uma graduação profissional.

\section{Organização e atuação \\ do Colegiado do Curso}

A composição inicial do Colegiado incluía as duas professoras do IHAC que atuavam na área de saúde, um representante do corpo docente dos demais BI e os representantes dos estudantes. Coube a essa representação estudantil a organização do Centro Acadêmico (CABIS), que passou a atuar na gestão do curso e a participar na gestão do IHAC, através dos seus representantes na Congregação ampliada.

No primeiro ano de funcionamento foram agregados ao Colegiado representantes do Instituto de Ciências da Saúde (ICS), Instituto de Saúde Coletiva (ISC), Escola de Nutrição, Escola de Medicina Veterinária, Faculdade de Educação e Faculdade de Odontologia. As Faculdades de Medicina, Enfermagem e Farmácia, entretanto, não encaminharam representantes, expressan- do, implicitamente, o desinteresse em participar da implantação do curso.

A principal atividade do Colegiado tem sido o planejamento acadêmico semestral da oferta de componentes curriculares, processo que implica intensa negociação com outras unidades acadêmicas, visando garantir vagas em componentes curriculares classificados como "culturas" e disciplinas optativas e livres. Além disso, o Colegiado desencadeou, junto a unidades acadêmicas da área de Saúde (ICS e ISC), a organização de áreas de concentração, isto é, a oferta de componentes curriculares que formam uma determinada área de conhecimentos e/ou direciona o aluno para um determinado curso profissional.

Durante o ano de 2011 o debate em torno dos procedimentos e critérios de ingresso nos demais cursos, denominados Cursos de Progressão Linear (CPL), foi intensificado nos Colegiados e na Congregação do IHAC, tendo em vista a operacionalização da Resolução aprovada pelo Conselho Universitário em 2008, que estabelece a reserva de pelo menos $20 \%$ das vagas de todos os cursos da UFBA aos egressos dos $\mathrm{BI}^{24}$. O Conselho Acadêmico de Ensino determinou que os aspectos a serem levados em consideração pelos Colegiados dos cursos, para aceitarem a matrícula dos egressos dos BI, deveriam enfatizar a apreciação do coeficiente de rendimento acadêmico, ponderado pela trajetória do aluno no curso, privilegiando a concentração de componentes do CPL pretendido $^{28}$. Tal decisão reativou o debate interno no IHAC em torno da restrição dos BI à sua finalidade propedêutica, à condução do alunado para uma escolha profissional precoce (a fim de garantir uma pontuação maior no momento da seleção para o CPL) e produziu insatisfação quanto à impossibilidade de se fazer, no momento de conclusão do curso, a transição para uma profissão de outra área do conhecimento.

Em meio a esse processo, o mandato da coordenação e vice-coordenação do Colegiado do curso eleita em 2009 foi encerrado, em agosto de 2011, sendo que as novas coordenadoras assumiram o mandato em setembro de 2011.

\section{Execução do Projeto Pedagógico do BIS 2009-2011}

Tomando como referência a trajetória da turma que ingressou em 2009 e concluiu em 2011, pode-se visualizar, no Quadro 3, o conjunto de componentes curriculares oferecidos e executados nos diversos eixos do curso. 
Quadro 3. Fluxograma do Bi Saúde 2009-2011.

\begin{tabular}{|c|c|c|}
\hline $1^{\circ}$ Semestre (2009.1) & 20 Semestre (2009.2) & 3o Semestre (2010.1) \\
\hline $\begin{array}{l}\text { HAC A10 - Introdução ao Campo } \\
\text { da Saúde }\end{array}$ & $\begin{array}{l}\text { HAC A40 - Campo da Saúde: } \\
\text { Saberes e Práticas }\end{array}$ & $\begin{array}{l}\text { HAC B17 - Saúde, } \\
\text { Educação e Trabalho }\end{array}$ \\
\hline Cultura 1 & Cultura 2 & Cultura 3 \\
\hline $\begin{array}{l}\text { HAC A01 - Estudos sobre a } \\
\text { Contemporaneidade I }\end{array}$ & $\begin{array}{l}\text { HAC A34 - Estudos sobre a } \\
\text { Contemporaneidade II }\end{array}$ & Cultura 4 \\
\hline Componente Livre & Componente Livre & Componente Livre \\
\hline $\begin{array}{l}\text { LET E43 - Língua Portuguesa, } \\
\text { Poder e Diversidade Cultural }\end{array}$ & $\begin{array}{l}\text { LET E45 - Leitura e Produção } \\
\text { de Textos em Língua Portuguesa }\end{array}$ & $\begin{array}{l}\text { HAC A78 - Oficina de } \\
\text { Textos Acadêmicos e } \\
\text { Técnicos em Saúde }\end{array}$ \\
\hline \multicolumn{3}{|c|}{ Atividades Complementares 180 horas (em 3 semestres) } \\
\hline $4^{\circ}$ Semestre (2010.2) & $5^{\circ}$ Semestre (2011.1) & $6^{\circ}$ Semestre (2011.2) \\
\hline Optativa da Área de Saúde & Optativa da Área de Saúde & Optativa da Área de Saúde \\
\hline Optativa da Área de Saúde & Optativa da Área de Saúde & Optativa da Área de Saúde \\
\hline Optativa da Área de Saúde & Optativa da Área de Saúde & Optativa da Área de Saúde \\
\hline Optativa da Área de Saúde & Optativa da Área de Saúde & Componente Livre \\
\hline Componente Livre & Componente Livre & Componente Livre \\
\hline
\end{tabular}

No Eixo Interdisciplinar, os Estudos da contemporaneidade I (2009.1) e II (2009.2) foram ministrados no primeiro semestre por uma docente da área de saúde (2 turmas) e, no segundo semestre, ficaram sob a responsabilidade de outros docentes do IHAC, da área de Humanidades. Os conteúdos abordados incluíram temas como "Globalização", "Corpo", "Identidade e Subjetividade", "Política”, "Economia e Mercado", "Ciência e Tecnologia", tratando-se de introduzir os estudantes a uma abordagem interdisciplinar, ao tempo em que se estimulava que cada grupo de alunos aproximasse o tema geral ao campo da Saúde.

O debate sobre "Globalização" partiu da revisão do pensamento de Milton Santos e contemplou as repercussões desse processo na saúde da população mundial, destacando-se a temática das epidemias e pandemias. $\mathrm{O}$ estudo do tema "Corpo" resgatou a historicidade dos estudos sobre o corpo humano, desde o surgimento da Anatomia até o debate atual no âmbito da
Sociologia do $\operatorname{corpo}^{29}$, conduzindo à reflexão acerca das concepções do corpo adotadas nas ciências da saúde. O debate sobre "Política" conduziu à reflexão sobre as Políticas de saúde no Brasil, discutindo-se o processo de Reforma Sanitária Brasileira ${ }^{30}$ e o tema "Mercado" contemplou os determinantes da organização dos sistemas de saúde no mundo ocidental e no Brasil, destacandose a coexistência do SUS e do Sistema de Assistência Médica Supletiva².

O estudo da "Ciência e Tecnologia" partiu da análise da revolução científica e tecnológica no mundo contemporâneo e as características atuais das práticas de saúde, marcadas pela intensa incorporação de tecnologias, tanto no âmbito da clínica (métodos diagnósticos e produtos terapêuticos), quanto no âmbito da saúde coletiva (promoção da saúde e prevenção de riscos), exemplificando-se com o debate sobre os modelos de atenção à saúde ${ }^{31}$ e a problemática relativa à produção, distribuição e consumo de medicamentos ${ }^{32}$. 
Paralelamente, os alunos cursaram os componentes curriculares do Eixo Linguagens, Lingua portuguesa, poder e diversidade cultural (2009.1) e Leitura e produção de textos em língua portuguesa (2009.2), os quais se constituíram em espaço de reapropriação crítica dos fundamentos da língua, o que por vezes gerou certo estranhamento e resistência dos alunos. Esse eixo completou-se em 2010, com a Oficina de Textos acadêmicos e técnicos em saúde, voltada a familiarizar o estudante com a linguagem científica e técnica da área, através da leitura e análise crítica de artigos, projetos, planos, relatórios, etc.

A inserção dos estudantes em componentes do Eixo Culturas, notadamente aqueles oferecidos pelas áreas de Humanidades e Artes, contribuiu para a exposição dos alunos a conteúdos que fundamentaram os debates ocorridos nas atividades desenvolvidas no Eixo da formação específica em Saúde. Assim, nos componentes Introdução ao campo da saúde e Campo da Saúde, oferecidos em 2009, tomou-se como fio condutor a historicidade do conceito de Saúde ${ }^{33,34}$, contemplando o debate das abordagens contemporâneas ao conceito ${ }^{35,36}$, bem como às noções de risco, vulnerabilidade, prevenção e promoção da saúde ${ }^{37-41}$. Em seguida foram abordados conteúdos relativos à situação de saúde da população brasileira e à problemática da organização dos sistemas de saúde no mundo e no Brasil, tema que conduziu ao debate sobre os movimentos sociais no campo da saúde, com ênfase na Reforma Sanitária Brasileira e no processo de construção do SUS ${ }^{2,30,42}$.

$\mathrm{Na}$ sequência, foi ofertado o componente curricular optativo Racionalidades em saúde: sistemas médicos e práticas alternativas, abordando-se as características dos diversos "sistemas médicos" e práticas contempladas na Política Nacional de Práticas Integrativas e Complementares do SUS. No segundo semestre de 2010, foi oferecido o componente Saúde, Educação e Trabalho, que discute as características das profissões da área de saúde e as tendências da formação e do mercado de trabalho no setor, reflexão apoiada em textos sobre o tema e palestras com profissionais convidados.

Além dos componentes curriculares obrigatórios, os alunos da turma de 2009 tiveram acesso a um conjunto heterogêneo de componentes curriculares optativos da área de saúde, destacando-se os que foram oferecidos pelo ICS, notadamente as disciplinas que constituem o ensino básico dos cursos profissionais da área de saúde, como Anatomia, Bioquímica, Imunolo- gia; os componentes oferecidos pelo ISC, a exemplo de Teorias Sociais em Saúde e pela Escola de Nutrição, como Aspectos Sócio-culturais da Alimentação e da Nutrição; os componentes oferecidos pelo próprio IHAC, como Seminários Interdisciplinares de Pesquisa em Saúde, Saúde e Cidade, Tópicos Especiais em Saúde; dentre outros.

Tudo isso, conjugado às aulas de música, dança, teatro, canto, cinema, meio ambiente, tecnologia, educação, línguas estrangeiras, psicologia, gênero, filosofia e ciências sociais, que conformaram os componentes livres e o eixo das "culturas", produziu uma rica trajetória de formação acadêmica, desenhada, em seu detalhamento, pelas escolhas dos estudantes.

Finalmente, quanto ao monitoramento das "Atividades Complementares" realizadas pelos alunos, foi organizado, um "dossiê" de cada um, contendo cópia dos documentos comprobatórios da realização destas atividades, o qual passou a ser analisado periodicamente, com vistas à contabilização da carga horária completada por cada estudante e posterior apreciação pelo Colegiado de curso, para integralização ao respectivo currículo.

\section{Problemas enfrentados e desafios para a consolidação do BI Saúde}

A implantação do BIS vem se dando em um contexto institucional complexo, no qual a coordenação, os docentes e alunos do curso se envolvem com processos mais gerais de organização e gestão do IHAC e com a implantação dos demais Bacharelados Interdisciplinares. Nesse contexto, aparecem problemas decorrentes das relações estabelecidas no ambiente interno do IHAC, bem como das relações estabelecidas com as demais unidades universitárias e com as instâncias superiores da administração da UFBA.

Tais problemas, entretanto, ganham significado distinto, de acordo com a perspectiva adotada pelos diversos atores envolvidos. Assim é que, na perspectiva dos estudantes, os problemas mais importantes foram, de um lado, a definição dos critérios e dos procedimentos para ingresso posterior nos CPL e, de outro, a inquietação quanto à possibilidade ou não de inserção no mercado de trabalho em saúde, uma vez tendo concluído o curso.

Para a coordenação do curso, os maiores problemas foram as dificuldades enfrentadas na adaptação do "projeto original" às condições concretas da instituição e as resistências de algumas instâncias superiores da UFBA e de algumas unidades 
acadêmicas da área de Saúde na operacionalização do curso. Do ponto de vista da equipe docente, os maiores problemas decorreram da sobrecarga de trabalho derivada do número exíguo de professores em 2009, a turbulência causada pela concomitância entre a elaboração do projeto pedagógico e a implantação do mesmo, as deficiências de infraestrutura e a instabilidade política vivenciada no processo de implantação do Instituto.

O problema maior, porém, que afeta direta e indiretamente a todos os sujeitos envolvidos no processo de implantação do $\mathrm{BI}$, diz respeito à tensão que se estabeleceu na UFBA entre o modelo de formação superior vigente na maioria das unidades acadêmicas e cursos, ou seja, o modelo que enfatiza a organização do conhecimento por disciplinas e a formação profissional voltada para a inserção dos egressos no mercado de trabalho, e o modelo proposto pelo BI, de caráter interdisciplinar, sem subordinação imediata à fragmentação que caracteriza a formação profissional nas diversas áreas.

Ainda é cedo para sabermos como essa tensão será resolvida, se tenderá à convivência construtiva entre os dois modelos, com o fortalecimento do projeto dos BI e a implantação definitiva do regime de ciclos, ou se tenderá à coexistência competitiva entre o BIS e os demais cursos da área de saúde, de modo a este se configurar como apenas mais um entre os cursos da área.

\section{Comentários finais}

O processo de implantação do BIS ilustra as vicissitudes enfrentadas no cotidiano de uma "organização hipercomplexa"43, como é o caso da UFBA, quando se pretende introduzir mudanças substantivas na arquitetura acadêmica e, sobretudo, quando se pretende experimentar um modelo de formação que contraria a tradição estabelecida na instituição.

A experiência relatada revela a possibilidade de se aproveitar certas "janelas de oportunidade" 19 , como foi o caso da confluência dos interesses materializados no projeto REUNI, notadamente a expansão e o fortalecimento das universidades públicas, e a presença de um grupo dirigente portador de um projeto de mudança institucional que ultrapassa a ampliação do número de vagas e cursos. A criação do BIS, especificamente, expressa a liderança exercida neste grupo de um intelectual do campo da saúde que já vinha desenvolvendo uma reflexão sobre a ne- cessidade de mudança nos processos de formação no campo ${ }^{44}$.

A análise do projeto pedagógico do BIS evidencia a negociação coletiva em torno dos diversos itens preservados ou modificados no "projeto original”, efetuando-se uma espécie de construção de viabilidade de implantação, mediada pelas concepções e práticas derivadas da experiência - diversificada - dos docentes e dirigentes envolvidos. O projeto pedagógico aprovado preserva o essencial da proposta, ao tempo em que define mais claramente os conteúdos específicos da formação em saúde, revelando, entretanto, uma aproximação maior aos conhecimentos e práticas da área de Saúde Coletiva, do que à clínica e às ciências básicas do campo da saúde, talvez em função do perfil acadêmico das professoras que assumiram a coordenação do Colegiado.

Cabe ressaltar a incorporação do uso de metodologias ativas no processo ensino-aprendizagem, estimulando-se o protagonismo dos estudantes, a responsabilidade com sua formação, o esforço de problematização das questões de Saúde na contemporaneidade, particularmente a realidade brasileira, ancorado na utilização em larga escala de tecnologias de informação que conectam os alunos e docentes à sociedade de conhecimento, notadamente a Internet. Nessa perspectiva, o Projeto Pedagógico do BIS propõe que os estudantes sejam expostos a um campo complexo, fornecendo instrumentos para que se coloquem como sujeitos autônomos, capazes de "pensar pela própria cabeça" e tomar posição diante das opções teóricas e práticas que se apresentam na área de saúde no mundo e no Brasil hoje.

Apesar das dificuldades enfrentadas no processo de implantação do curso, o BIS constitui um espaço de formação universitária de caráter introdutório ao campo da saúde, enfatizando a apropriação de conhecimento e desenvolvimento de habilidades e valores que contemplam a compreensão da dimensão histórica e social das concepções e práticas de saúde, contribuindo assim para o enriquecimento, a humanização e o aprimoramento da futura formação profissional nesta área. Ademais, permite ao estudante situar-se e sensibilizar-se com relação aos determinantes sociais dos problemas de saúde, às propostas de enfrentamento destes, configuradas nas políticas formuladas e implementadas no âmbito dos sistemas de saúde, e à configuração do mercado de trabalho para as distintas profissões da área, de modo a poder decidir, com mais clareza, o rumo que pretende imprimir à sua vida do ponto de vista intelectual, profissional e político. 


\section{Colaboradores}

CFS Teixeira, MTAD Coelho e MND Rocha participaram igualmente da concepção do projeto, da produção e análise dos dados e da redação da versão final.

\section{Referências}

1. Paim JS, Travassos C, Almeida C, Bahia L, Macinko J. O sistema de saúde brasileiro: história, avanços e desafios. Lancet 2011; Saúde no Brasil 1(maio):11-33.

2. Bahia L. O SUS e os desafios da universalização do direito à saúde: tensões e padrões de convivência entre o público e o privado no sistema de saúde brasileiro. In: Lima NT, Gerschman S, Edler FC, Suárez JC, organizadores. Saúde e Democracia: história e perspectivas do SUS. Rio de Janeiro: Fiocruz; 2005. p. 407-449.

3. Santos IS, Ugá MADE, Porto SM. O mix públicoprivado no Sistema de Saúde Brasileiro: financiamento, oferta e utilização de serviços de saúde. Cien Saude Colet 2008; 13(5):1431-1440.

4. Pierantoni CR, Varella TC, França T. Recursos humanos e gestão do trabalho em saúde: da teoria para a prática. In: Barros AFR, Santana JP, Santos Neto PM, organizadores. Observatório de recursos humanos em saúde no Brasil: estudos e análises, vol. 2. Brasília: Ministério da Saúde; 2004. p.51-70.

5. Pierantoni CR, Varella TC, França T, Garcia AC. Gestão do trabalho e da educação em saúde: recursos humanos em duas décadas de SUS. Physis 2008; 18(4): 685-704.

6. Haddad AE, Morita, MC, Pierantoni CR, Brenelli SL, Passarela T, Campos FE. Formação de profissionais de saúde no Brasil: uma análise no período de 1991 a 2008. Revista Saúde Pública 2010; 44(3):383393.

7. Brasil. Lei no 9.394 de 24 de dezembro de 1996. Lei de diretrizes e bases da educação. Diário Oficial da União 1996; $24 \mathrm{dez}$.

8. Pinheiro R, Ceccim RB, Mattos RA. Ensinar saúde: a integralidade e o SUS nos cursos de graduação na área da saúde. Rio de Janeiro: IMS,UERJ,Abrasco; 2005.

9. Pinto ICM, Teixeira CF. Formulação da Política de Gestão do Trabalho e Educação na Saúde: o caso da Secretaria Estadual de Saúde da Bahia, Brasil, 2007-2008. Cad. Saúde Pública 2011; 27(9):1777-1788.

10. Teixeira CF, Vilasbôas AL. Desafios da formação técnica ética dos profissionais das equipes de Saúde da Família. In: Trad LA, organizadora. Família contemporânea e saúde: significados, práticas e políticas públicas. Rio de Janeiro: Fiocruz; 2010. p. 133-156.

11. Santos BS. Da idéia de universidade à universidade de idéias. In: Santos BS. Pela mão de Alice: o social e o político na pós-modernidade. 4a Edição. São Paulo: Cortez Editora; 1997. p. 187-233.

12. Santos BS, Almeida Filho N. A Universidade no século XXI: para uma Universidade nova. AlmedinaCES: Coimbra; 2008.

13. Morin E. A cabeça bem-feita: repensar a reforma, reformar o pensamento. $4^{\text {a }}$ Edição. Rio de Janeiro: Bertrand Brasil; 2001.

14. Morin E. A religação dos saberes: o desafio do século XXI. 2a Edição. Rio de Janeiro: Bertrand Brasil; 2002.

15. Morin E. Introdução ao pensamento complexo. $4^{\mathrm{a}}$ Edição. Lisboa: Instituto Piaget; 2003.

16. Morin E. Os sete saberes necessários à educação do futuro. 10a Edição. São Paulo. Brasília: Cortez Editora, UNESCO; 2005. 
17. Almeida Filho N. Universidade nova: textos críticos e esperançosos. Brasília, Salvador: UnB, Edufba; 2007.

18. Universidade Federal da Bahia(UFBA). Universidade Nova: reestruturação da arquitetura curricular da educação superior no Brasil. [Minuta de anteprojeto]. Salvador: UFBA; 2006.

19. Kingdon JW. Agendas, Alternatives and Public Policies. United States of America: Addison-Wesley Longman; 1995.

20. Capella ACN. Perspectivas teóricas sobre o processo de formulação de Políticas Públicas. In: Hochman G, Arretche M, Marques E, organizadores. Políticas Públicas no Brasil. Rio de Janeiro: Fiocruz, 2007. p. 87-122.

21. Universidade Federal da Bahia. Proposta de inclusão da Universidade Federal da Bahia no Programa de Apoio a Planos de Reestruturação e Expansão das Universidades Federais. Salvador; 2007.

22. Universidade Federal da Bahia (UFBA). Projeto Pedagógico dos Bacharelados Interdisciplinares. Salvador: UFBA; 2008

23. Universidade Federal da Bahia (UFBA). Memorial da Universidade Nova: UFBA 2002-2010. Salvador: UFBA; 2010.

24. Universidade Federal da Bahia (UFBA). Conselho de ensino, pesquisa e extensão. Resolução 02/2008. Salvador: UFBA; 2008.

25. Almeida Filho N. Matriz curricular do Bacharelado Interdisciplinar em Saúde. [slides]; 2008. 39 Slides.

26. Almeida Filho N. A Epidemiologia e o campo da saúde: interfaces disciplinares. In: Almeida Filho N, Barreto ML, organizadores. Epidemiologia \& Saúde: Fundamentos, Métodos e Aplicações. Rio de Janeiro: Guanabara Koogan; 2011. p. 55-64.

27. Universidade Federal da Bahia (UFBA). IHAC. Projeto Pedagógico do Bacharelado Interdisciplinar em Saúde. Salvador: UFBA; 2010.

28. Universidade Federal da Bahia (UFBA). Conselho acadêmico de ensino. Resolução $n^{o}$ 6/2011. Salvador: UFBA; 2011.

29. Breton DL. A sociologia do corpo. Petrópolis: Vozes; 2006.

30. Paim JS. Reforma Sanitária Brasileira: contribuição para compreensão e crítica. Salvador, Rio de Janeiro: Edufba, Fiocruz; 2008

31. Teixeira CF, Solla JP. Modelo de Atenção à saúde no SUS: trajetória do debate conceitual, situação atual, desafios e perspectivas. In: Teixeira CF, Solla JP, organizadores. Modelo de atenção à saúde: promoção, Vigilância e Saúde da Família. Salvador: Edufba; 2006. p. 129-167.

32. Rosenfeld S. O uso de medicamentos no Brasil. In: Laporte JR, Tognon G, Rosenfeld S, organizadores. Epidemiologia de medicamentos. São Paulo: Hucitec; Rio de Janeiro: Abrasco; 1989. p. 21-39.

33. Batistella C. Saúde, doença e cuidado: complexidade teórica e necessidade histórica. In: Fonseca $\mathrm{AF}$, Corbo $\mathrm{AD}$, organizadores. O território e o processo saúde-doença. Rio de Janeiro: EPSJV, Fiocruz; 2007. p. 25-49.

34. Scliar M. História do conceito de saúde. Physis 2007; 17(1):29-42
35. Coelho MTAD, Almeida Filho N. Conceitos de saúde em discursos contemporâneos de referência científica. Hist, cienc. saúde - Manguinhos 2002; 9(2): 315-333.

36. Batistella C. Abordagens contemporâneas do conceito de saúde. In: Fonseca AF, Corbo AD, organizadores. O território e o processo saúde-doença. Rio de Janeiro: EPSJV,Fiocruz; 2007. p. 51-86.

37. Almeida Filho N. Desconstruindo o conceito de risco. In: Almeida Filho N. A Clínica e a Epidemiologia. 2a Edição. Salvador. Rio de Janeiro. São Paulo: APCE, Abrasco; 1997. p. 123-152.

38. Ayres JRCM, França Junior I, Calazans GJ, Saletti Filho HC. O conceito de vulnerabilidade e as práticas de saúde: novas perspectivas e desafios. In: Cze resnia D, Freitas CM, organizadores. Promoção da saúde: conceitos, reflexões, tendências. Rio de Janeiro: Fiocruz; 2003. p. 117-139.

39. Buss PM. Uma introdução ao conceito de promoção da saúde In: Czeresnia D, Freitas CM, organizadores. Promoção da saúde: conceitos, reflexões, tendências. Rio de Janeiro: Fiocruz; 2003. p. 15-38.

40. Czeresnia D. O conceito de saúde e a diferença entre prevenção e promoção. In: Czeresnia D, Freitas CM, organizadores. Promoção da saúde: conceitos, reflexões, tendências. Rio de Janeiro: Fiocruz; 2003. p. 39-53.

41. Gondim G. Do conceito de risco ou da precaução: entre determinantes e incertezas. In: Fonseca AF Corbo $\mathrm{AD}$, organizadores. $O$ território e o processo saúde-doença. Rio de Janeiro: EPSJV, Fiocruz; 2007. p. 87-119.

42. Barreto ML, Carmo EH. Padrões de adoecimento e de morte da população brasileira: os renovados desafios para o Sistema Único de Saúde. Cien Saude Colet 2007; 12(Supl.):1779-1790.

43. Testa M. Analisis de instituciones hipercomplejas. In: Merhy EE, Onocko R, organizadores. Praxis en salud: un desafio para lo público. São Paulo: Hucitec; 1997. p. 17-70.

44. Teixeira CF. Naomar de Almeida Filho (2002 - 2010). In: Toutain LMB, Varela MAA, organizadoras. Reitores da UFBA: de Edgard Santos a Naomar de Almeida Filho. Salvador: EDUFBA; 2011. p. 261-286.

Artigo apresentado em 24/09/2012

Aprovado em 31/10/2012

Versão final apresentada em 20/11/2012 